\title{
ERNÄHRUNG
}

\section{Zuckerzusatz schlecht für Blutfette}

Dass fettreiche Ernährung die Serumlipide ungünstig beeinflussen kann, ist wenig überraschend. Dasselbe gilt aber auch für zuckerhaltige Lebensmittel, wie eine US-Studie mit mehr als 6000 Erwachsenen belegt. In der Studie war ein erhöhter Konsum von gesüßten Lebensmitteln (meist mit Saccharose oder Fructose) mit einem Anstieg der Triglyzeride und einer
Abnahme des HDL-Cholesterins assoziiert. Im Durchschnitt stammten rund 16\% der täglich aufgenommenen Kalorien aus Nahrungsmitteln mit Zuckerzusätzen. Nach einer Empfehlung der American Heart Association sollten es aber deutlich weniger sein, nämlich maximal $140 \mathrm{kcal}$ bei Männern bzw. $100 \mathrm{kcal}$ bei Frauen. JAMA 2010;303(15):1490-1497

\section{ZU WIRKUNGEN UND NEBENWIRKUNGEN ...} \section{... frag besser nicht den Apotheker?}

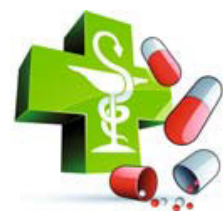

Versandapotheken und Apothekenkooperationen nahm die Stiftung Warentest unter die Lupe. Beratung, Service und Preisgestaltung wurden überprüft. Von 50 getesteten Apotheken wurden elf (drei Vor-Ort- und acht Versand-Apotheken) mit „mangelhaft“ bewertet. Ihr Fehler: Sie machten Testkäufer nicht auf Wechselwirkungen der gekauften Präparate aufmerksam oder interessierten sich beim Kauf eines fiebersenkenden Mittels für

ein dreijähriges Kind nicht einmal für die Höhe des Fiebers. Die Beratung in der Apotheke ist meist nicht fehlerfrei und selten diskret. Bemängelt wird vor allem die fehlende Diskretion. Preislich sind Versandapotheken oft, aber keineswegs immer am günstigsten. Kleine Preisvorteile werden häufig durch die Versandkosten zunichte gemacht.

Apotheken - selten gut beraten. Stiftung Warentest, www.test.de

\section{REISEMEDIZIN}

\section{Darf die Insulinspritze mit ins Flugzeug?}

Die Sicherheitsbestimmungen im Flugreiseverkehr können für Patienten, die Medikamente mit an Bord nehmen müssen, auf Hilfsmittel angewiesen sind oder einen Herzschrittmacher haben, problematisch sein, zumal sich die Bestimmungen häufig ändern. Besonders streng werden Reisende in den USA kontrolliert. Für Patienten, die hier Rat brauchen, können Sie sich auf der Webseite der Transportation Security Administration (TSA) über den aktuellen Stand informieren. Patientinnen mit Brustaugmentation können Sie übrigens beruhigen: Deren Implantate dürfen mit an Bord.

http://www.tsa.gov/travelers/airtravel/specialneeds/index.shtm

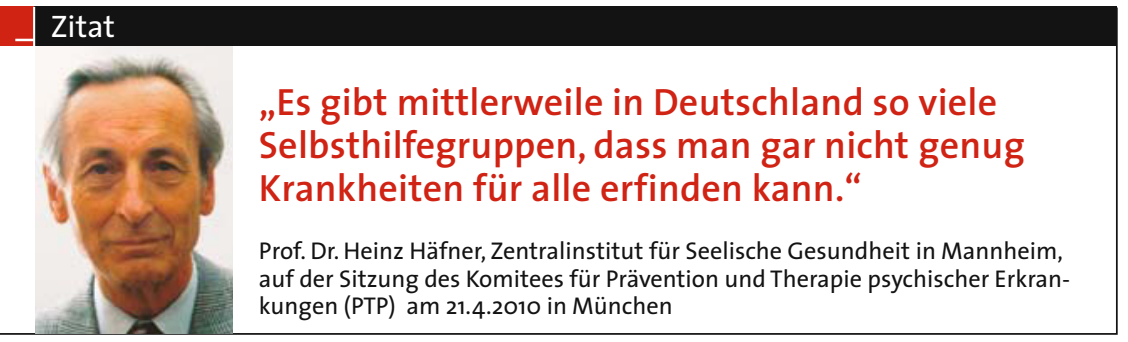

Dr. med. Dirk Einecke

Chefredakteur

\section{CHRONISCHE RHINOSINUSITIS}

\section{Raus aus der Raucherzone!}

Wenn ein Patient zu chronischer Rhinosinusitis neigt, sollte er nicht nur aufs Rauchen verzichten, sondern auch das Passivrauchen vermeiden. Wer häufiger von anderen eingequalmt wird, hat nämlich auch ein höheres Risiko, chronische Entzündungen der Nasennebenhöhlen zu entwickeln. In einer Fall-Kontroll-Studie mit 612 Personen, alles Nichtraucher, war Passivrauchen schon bei mäßiger Exposition ein entscheidender Risikofaktor.

Arch Otolaryngol Head Neck Surg. 2010; 136(4):327-34

\section{DEPRESSONSTHERAPIE BEI KHK}

\section{Seele und Herz danken es}

Patienten mit akutem Koronarsyndrom haben eine schlechtere Prognose, wenn sie unter depressiven Symptomen leiden. Dass eine adäquate antidepressive Therapie in diesen Fällen nicht nur das subjektive Befinden, sondern auch den Verlauf der Herzerkrankung bessert, zeigte eine randomisierte Studie mit 237 Patienten mit akutem Koronarsymptom. 157 von ihnen litten an einer Depression und wurden entweder psycho- und pharmakotherapeutisch behandelt oder erhielten nur die übliche Betreuung. Patienten der Interventionsgruppe erlitten im sechsmonatigen Studienverlauf signifikant weniger kardiologische Ereignisse als die Patienten der Kontrollgruppe.

Arch Intern Med. 2010;170(7):600-608 